\title{
On the General Characteristics of Sinology Researches in Turkey
}

\author{
Eyüp Saritaş \\ Department of Chinese, Istanbul University, Istanbul, Turkey
}

Email address:

eyupsaritas1991@hotmail.com

\section{To cite this article:}

Eyüp Saritaş. On the General Characteristics of Sinology Researches in Turkey. Humanities and Social Sciences. Vol. 3, No. 6, 2015, pp. 293-298. doi: 10.11648/j.hss.20150306.12

\begin{abstract}
As once expressed by the German Sinologist Prof. Dr. Wolfram Eberhard, Sinology is a national discipline for the Turks simply because it is the Chinese sources that provide the most extensive and elaborative records on the ancient Turkish history and culture. Well then, do we, the Turkish sinologists, give due consideration to sinology researches, which function as in integral part of the Turkish history and culture? Sadly, answer to this question is most of the time not affirmative. Even though Wolfram Eberhard levelled up the Turkish sinology to an international scale during his office at Ankara University in 1937-1948, the methods initiated by him could not be resumed after his departure from Turkey, which in turn, resulted in stagnation of the discipline. The fact that sinology researches do not run complementary to one another, and failure to publish research results - which absolutely take great efforts, time and energy- and to make them available for and accessible to a large mass, discipline's failure to come up with long-lasting works that would pave the ground for further researches for the Turkish culture, that native sinologists cannot employ an extensive perspective to sinology researches, and either fail or are unwilling to establish principles with regards to scientific methods utilised to this end can be listed amongst the primary reasons for the aforecited stagnation. Rising generation of the Turkish sinologists were thus deprived of toponomy, titles, personalities and fundamental Chinese works of conventional and modern era that were supposed to be available for them to conduct researches in their field of interest. In this work, it is intended to present an outline of contemporary sinology researches in Turkey.
\end{abstract}

Keywords: Sinology, Turkey, Characteristic

\section{Introduction}

As is known, Chinese civilisation is one of the ancient, which still survives. China has a firm and solid tradition of state for thousands of years, has exquisite funds of knowledge and experience in the world's oldest and richest record keeping, and has been historically, culturally, economically and politically involved with the neighbouring Huns, Mongols, Tibetans amongst many other tribes interalia their own culture. For this reason sinology researches constitute one of the most popular academic disciplines. Recent economic growth and improvement in China, and dynamics of international relationships have undoubtedly been influential on popularity of this scientific field. In this limited work, however, general characteristics of the sinology researches conducted in Turkey up until today will be considered and analysed from a critical point of view with a concentration as to how academic studies in this discipline function to serve the purposes of sinology in Turkey, as well as the methods employed for sinology researches in Turkey, rather than the aforecited particularly.

Sinology researches in Turkey, which were initiated 80 years ago and lasted until 1948 when Eberhard departed from our country, were on an international level. Prof. Dr. Wolfram Eberhard, and Prof. Dr. Bahaeddin Ögel deserve the largest share for catching up with the golden age in Turkish sinology. Prof. Eberhard made utterly precious and greatest efforts for the establishment and development of the discipline in Turkey, and the times when he held office in our country can be referred to as the golden era of the Turkish sinology as he produced a wide range of and elaborative works including without limited to the ethnology of the Turkish history, Turkish-Chinese relationship, Chinese literature, ensuring that the discipline takes hold in Turkey.

Figuring out the importance of sinology as a discipline for the Turkish history and culture, Prof. Dr. Eberhard produced 
very precious points regarding the Turkish-Chinese cultural interactions. According to Eberhard, sheerly different political improvement between the North China, which is composed of pure Chinese people, and North China, which rather is under dominance of the Turks, paved the ground for the same when it came to literature, too. In North China, local Turkish songs were being imitated; songs composed in a natural and colloquial language and addressing strong feelings and expressions emerged at the time. Indeed, poetry of the Tang dynasty period, which was overwhelmed with deep emotions and sensuality under the influence of the south, was revealed $b$ the influence of the Turkish literature. The very first Tang poet that pointed out to such new formation of poetry was Zhen Ze'ang (Eberhard, 1995: 219). Bahaeddin Ögel prepared his doctoral thesis titled "Uygurların Menşe Efsanesi (Uyghurs Myths of Origin)" under the guidance of Wolfram Eberhard (Göde, 1989: 453).

Although Prof. Ögel, who was a student of, consequently a follow-up to Eberhard, did not prefer works on the Chinese culture as sinologists did, whereas he penned works on the Turkish history of Central Asia by relying on the Chinese sources, he also made great contributions to the Turkish Sinology.

On taking a quick look at the general characteristics, it can be easily observed that researches are not timeless but are skin-deep academic studies, failing to run complementary to the precedents. Primary reason for this unfavourable fact is the lack of principles for sinology researches in Turkey. Academicians showed interested in many different themes of sinology rather than specialising in a specific field of the discipline, which, in turn, prevented them from in-depth discussions on a given subject. Likewise, this can be explained with the lack of a strong will for training qualified human power. For the absence of well management and administration, principles established by two veteran sinologists and historians as Prof. Dr. Wolfram Eberhard and Prof. Dr. Bahaeddin Ögel could not gain a seat in the scientific world in our country. Consequently, sinology researches were restricted to articles as of the first half of $20^{\text {th }}$ century. As it will be appreciated, having a qualified man power is a time-demanding process. From this perspective, failure to have satisfactory number of sinology experts qualified to make academic researches in sinology can be tolerated.

\section{Notional Framework}

In this study, even though the term Sinology' refers to a field of activity relating to China, which covers all aspects of the modern China as of the use of Chinese letters, the opinions pointing to precise lines amongst concepts such as "Sinology", "Chinese Researches" and "Guo Xue" prevail in China, a homeland to this academic discipline, in addition to a set of western countries particularly the United States of America, and Germany, France, the U.K., the Netherlands and Russia where the most extensive and influential works have so far been carried out. It points to the fact that all kinds of information for the modern China should be searches with regards to the concepts of Chinese Researches, Guo Xue. The term Sinology, however, refers to and covers a wider range of time compared to the concepts specified herein, and it points out to further researches of China including traditional and modern eras. Therefore, it can be argued that the term "Sinology" refers to scientific information systems on China starting from the earliest period of Chinese civilisation until today.

Employing a western perspective while conducting Sinology researches in our country, that is, discussing Sinology considerations from a westerner's point of view has become a trend as in the case with many other social sciences in our country. On considering it this way, the quality and features of sinology researches have been barely considered in our country, and the path of the westerner colleagues have been followed probably for cutting corners. Consequently, strong western countries that have made progress in industry and economy have come to a position to determine the approach and methods of all sinonologists or experts of China in the rest of the world. What is meant by this is detailed below.

When we were studying for a bachelor's degree in sinology, we used to think that the academic discipline, named sinology, did bear the same name in most part of the world if not in all of it. It was firstly in July 20015 when we visited the department of Chinese Researches at Leiden University in the Netherlands with a task to make researches on Chinese works that we came to figure out that the western countries already stopped using the term "sinology". Just like the term orientalism instead of eastern researches was no longer in use and was replaced by the term "Asian Studies" as the former implied exploitation of the east by the west until the first years of $20^{\text {th }}$ century, and the rest of the world was pressed to follow it.

\section{On the Concepts of "Sinology" and "China"}

It is a discipline wherein academicians from foreign countries - foreign to Chinese researchers- conduct researches on China. In Turkish, it suggests conducting researches on China outside China, and is called "Haiwai Zhongguoxue Yanjiu" (Chinese Studies in Overseas) in China. Interestingly, history of foreign scientists that seek to conduct searches on China is older than that of the Chinese people conducting researches on their homeland. Chinese academicians. Researches on China conducted by foreign academicians started in the first half of the $80 \mathrm{~s}$ during $20^{\text {th }}$ century. Chinese Government established a National Centre of Chinese Researches outside China for the sake of Chinese Researches, which were recognised as a national field of research. The research centre relied upon the Centre of Chinese Researches in Foreign Countries at the Foreign Languages University of Beijing. Established in 1996, the centre attaches maximum importance to Chinese researches 
particularly conducted in western countries. Over 60 works and over 100 dissertations on specific issues, articles and assays, translations and educational materials were published until today. (Zhang, 2012: 1)

Sinology: "Hanxue" in Chinese, sinology is the name of all researches conducted in foreign countries outside China in the fields of Chinese language and literature, history, way of thinking and religion. Sinologists around the world have not yet chronologically agreed on a mutual opinion regarding the contextual meaning and restrictions of the term "sinology". This, up to a certain point, depends on the contextual meaning assigned by a given country to the term, as well as on the characteristics of their understanding of sinology as a word. Considering that the word sinology means Hanxue in Chinese, it should not be misleading as if the word suggests researches conducted on the Han Dynasty. What is meant by the term sinology today is substantially the researches on a set of various cultural traits of China conducted by nonChinese sinologists as explained above. (Xiong, 2007: 4). Apart from the given definition, some experts on China use Zhongguoxue or Guoxue in brief instead of the term Sinology. These two terms are, in our opinion, the name given for scientific researches for contemporary China

Beginning of the discipline dates back to arrival of the Spanish sinologist Matteo Ricci in China, consequently sinology has a history over 400 years. The period of sinology researches until the time when contemporary China was finally being researched, is called the Period of Missionaries of Sinology as missionaries such as the Spanish missionary Matteo Ricci arrived in China and made attempts to get to know the country. (Meng, 2014: 93). Applauded as the master mind of the discipline of Sinology, Matteo Ricci stepped in Macao in 1580, and another Italian missionary namely Ruggieri, stepped in Guangzhou (Geng, 2015: 5).

Discipline of Chinese Language and Literature was included in the education in 1814 in France, followed by the U.K. and Germany. As sinology works were established and improved by German sinologists in Turkey, new generation Turkish sinologists raised by them also followed the methods formerly followed by the German sinologists in their scientific works. Consequently sinology works developed in Turkey were heavily influenced by the French and German sinologists. Unfortunately, very limited portion of in-depth research works conducted by the German and French sinologists in Turkey was translated to Turkish. Today, influence of the French and German Sinologists diminished markedly (Barthold, 2004: 192).

As it will be appreciated, Chinese researches form the basis of sinology researches. A striking feature of the $19^{\text {th }}$ century sinology researches is that they have been conducted in French and Dutch. Whether a sinologist has a high or poor level of sinology is measured by his or her background of the traditional Chinese. Level of knowledge for modern Chinese is accepted as complementary feature in support of further skills in the field. To clarify one significant point, a sinologist that is not capable of speaking Chinese but is capable of reading texts is destined to make mistakes repeatedly.
Consequently, an ideal sinologist should be capable of ruling over classical texts and should also be capable of speaking Modern Chinese (Liu, 2002, 21-22).

\section{Sinology as a National Discipline in Turkey}

Well-known German sinologist Prof. Dr. Wolfram Eberhard, who held office at the Sinology Department under the Department of Eastern Languages and Literatures at the Faculty of Languages, History and Geography in Ankara University in 1937-1948 was the first to come up with an opinion that sinology should be recognised as a national discipline in Turkey. Having been densely involved with the Turks as of the "Northern Di", known as the ancestors of the Huns; China has a unique civilisation that should be particularly known to Turks as it is the Chinese sources that offer the oldest and riches information on the Turkish history and culture since ancient times.

Already familiar with this fact, Atatürk made personal attempts to establish the sinology chair at Ankara University in 1935. At the time the most significant task appointed to the department was searching the ancient Turkish history and culture based on the Chinese sources through native sinologists that would be trained there. Consequently, outputs produced in Sinology in Turkey came up with extensive studies that served the purpose of establishment until the early 50s. The first work that deserves being mentioned in this context, is Çin'in Şimal Komşuları (Northern Neighbours of the West) written by Eberhard and published by the Institute of History in 1942. Eberhard believed that one should first of all try to under the history and culture of the tribes living in the north of China in order to fully comprehend the Chinese culture. For this reason, we wrote an almost systematic research work on the cultures of Huns, East Hula, Koreans and Tunguz. (Eberhard, 1996). This particular work is prominent it that it was written based on the first-hand annuals of Chinese dynasty. Providing information details especially on the tribes in the northern part of China, the work became a source of inspiration for Chinese-speaking historians in the forthcoming years, and paved the ground for monographies for a set of Turkish tribes.

The work ' Northern Neighbours of the West' was followed by two other works, namely 'Introduction to Sinology', and 'History of China'. These last two books were also written by Prof. Dr. Wolfram Eberhard. Published in 1946, the work 'Introduction to Sinology' provides precious information on the general characteristics of sinology as a discipline, importance of the discipline for the Turks and the extent of courses at the institutions where Chinese is taught. It also lights the way for sinologists as a guide (Eberhard, 1946). Today sinology researches are sought after in most of the western and eastern countries, it however leads us towards a negative general condition as far as the sinology in Turkey is concerned, that the very first and last books in sinology were 
written by a German scientist and subsequently published back in 1946, that native sinologists are not very much interested in the field. As sinology is qualified as a national discipline for the Turks, relevant works are supposed to be closely followed and further researches should be conducted to this end.

It is a quite well know as a fact to see why sinology is supposed to be a national discipline in Turkey. Even though the aforecited fact is recognised and accepted to be true, could we ever adopt a perspective that looks at the discipline as a field of national research? To what extent did we serve to sinology researches since 1935 when early sinology works were conducted? How did scientific researches proceed in a period of 80 years? Were results of researches in the field of Turkish sinology conducted almost for a century sufficiently and satisfactorily productive? What is the method of scientific research applied in our country for conducting sinology researches, which has a specific research method of its own? How should it be? Once and if these questions are answered objectively and accurately in details, the general condition of the sinology researches in Turkey, more specifically, the general condition of the works in the aforecited area, will have come to light.

\section{On the Tasks of Sinology in Turkey}

As formerly expressed, objective of establishment Department of Sinology in our country is to ensure Turkish sinologists translate to Turkish the relevant portions of the Turkish history and culture from Chinese sources by utilising scientific methods and to evaluate the same unbiasedly. Consequently, the curriculum of the department covers Chinese history, literature and philosophy starting from the traditional era, which holds a significant place for the rest of the programme. Then again, the first and second generation of sinologists, namely Wolframram Eberhard, Bahaeddin Ögel, Muhaddere Nabi Özerdim (The very first native sinologists raised in Turkey, Muhaddere Nabi Özerdim wrote up her doctoral dissertation titled "poetry of the Turks that Established a Dynasty in the North of China in Centuries 4-5 A.C." in 1943 under the guidance of Wolfram Eberhard, Sezen, 2012: 159) and Pulat Otkan in our country produced extensive or not-so-extensive worlds based on Chinese sources with a view to shed light onto Turkish history and culture. History of China, and Northern Neighbours of China are two reference works by Eberhard, written to make contributions to the Turkish history. Although the book 'History of China' examines, by content, the outlines of China as of the historical periods, it has actually examined the Chinese history from the perspective of the Turks. The Great Hun Empire, a two-volume work, written by Prof Dr. Baheddin Ögel and published in 1982 is a particularly good reference book for the enthusiasts of the subject. Detailed works of Ögel, less extensive than a book and yet more than an article with respect to political, economic and cultural relationship of the Huns with the Yuezhi, and the Wusunboth significant tribes of the Central Asia, are labour- intensive works derived from the sinology studies based on first-hand Chinese sources. In addition to this, the very first work in a book format, on the Chinese literature, which was co-translated by Eberhard and Nusret Hızır, is called Çin Denemeleri / Essays on China (Eberhard, 1989). The book gives prominent examples in a smooth and fluent language expanding to a wide range of time starting from the 4th century B.C. and until 19th century. Unfortunately, not much importance was given to translate works concentration on Chinese literature that would incorporate traditional Chinese literature with great reflections of the traditional period of Chinese culture, life style and thinking.

As it will be understood from what has been explained above, the department of sinology provided education in classical Chinese until 1971 when Turkey had diplomatic affairs with People's Republic of China, and endeavoured to train sinologists that would be capable of penetrate into the sources by way of classical Chinese information. Upon commencement of diplomatic affairs, modern Chinese courses were added to the curriculum to ensure that sinologists that graduate from the Department of Sinology enjoy a wide range of job opportunities and acquire information on modern China.

Once modern Chinese as being taught at sinology department in our country, the interest towards China increased, which was perceived to be even stronger rival cultural collaboration protocols executed by and between Turkey and People's Republic of China in the early 80 s. Within the framework of these protocols, researchers from both countries visited each others' homeland and endeavoured to conduct researches in their own field(s) of interest. The interest towards China in Turkey increased more especially after the opening policy, and this, in turn, paved the ground for publishing more works concentrating on China. Majority of the books that examine and scrutinise China from a set of aspects as of Eberhard's period until today is not sources and works originally relying on Chinese sources, but is second-hand research sources produced in English, German and French. There are hardly any works written on the Central Asian Turk amongst the works cited here.

\section{General Characteristics of Researches Conducted on China in Turkey}

Researches conducted on China in Turkey could never catch up with the level of those conducted by modern countries since the establishment of the Department of Sinology. This is merely because the cited academic field of study was deprived of a sufficient and satisfactory background and experience in our country. Neither experts nor units that selected this particular field of study fail to adopt a systematic and well-coordinated approach. Before proceeding with a more in-depth discussion into this, it would be beneficial to present a brief evaluation on the past and present targets and characteristics of the researches 
conducted on China in Turkey.

Enjoying enriched experience of nearly five centuries for the researches on China, the western world intended and made efforts to comprehend and grasp the people, language, religion, past, literature, art and China as a whole from the moment it became interested in it; and it further engaged in generating cultural assets of China from its own perspective, thus to gain favour out of them. Jesuit priests that served as missionaries, and merchants, travellers and scientists of different disciplines that turned their face to China, and even the commissions of explorers penned works on China, which evidently reveals how successful and dedicated the western world was for understanding, rephrasing and making benefits out of China.

Sinology researches initiated in Turkey in 1935 did unfortunately not set universal and wide-angle targets as western sinology researches did. It merely intended to and contended itself to determine and construe information on the history of the Hun, Gokturks and Uyghurs in addition to other Turkish communities as extracted from Chinese sources written at different times instead of understanding the Chinese history and culture, which is very vast by nature. It is quite normal that the Turks give priority mainly to scrutinising the Turkish history and culture based on the firsthand sources written in classical periods as they neighboured and were engaged with the Chinese for over 2000 years in many different aspects of life; it actually is needed, too. Nevertheless, sinology researches in Turkey were never put into a systemised and method of studying and researches since the beginning; the researches were often restrictive to skin-deep and surficial ones in the field. For instance, relevant sections of the Chinese sources with respect to the Huns and Gokturks - which constitute the first and second period of the ancient Turkish history- were not translated, thus were not evaluated sufficiently.

As explained hereinabove, the Turk and the Chinese have been engaged in a wide range of area since ancient times, thus one of the most important targets of the Turkish sinology should have functioned to understand the Chinese history and historians, literature and in brief, China a s a whole since the very beginning of the written history. This was never a target, though. Attitudes of the native researches that are reluctant to perform in-depth researches are what lies beneath.

Sinology researches in Turkey were predominantly confined to historical and literary texts written in Classical Chinese up until the early 1971, after which modern Chinese was added, though in a restricted manner, to the curriculum so that alumni have a better opportunity of jobs. As an inevitable effect of the opening policy of China, a very few number of researchers that studied at the universities concentrating on Chinese researches attached more importance to understand and comprehend the history and culture of China as in the western countries did, and came up with academic works in the field.

Although the caption above is GENERAL CHARACTERISTICS OF RESEARCHES CONDUCTED ON CHINA IN TURKEY," why do we still mention the characteristics of sinology studies in Turkey? Because the content and scope of Chinese studies in our court are determined by the curricula. Since the sinology studies are not in international levels in Turkey, scientific studies remain quite limited, and labour-intensive works cannot go beyond the limits of locality.

Good efforts were made to outline the general characteristics of the academic studies conducted on China in Turkey:

a) Majority of the researches conducted on China in Turkey is covered in "Sinology", whereas the ones covered by "researches on China" are very limited. Consequently, majority of sinology-oriented considerations rely on Chinese sources written at certain times.

b) No matter how detailed the sinology researches are, references are more commonly made to the works conducted by Germany, France, and the United States of America; not enough attention has been given to criticise research works conducted at modern times in China. For this reason, scientific researches in China and Taiwan were often missed out.

c) Our sinologists predominantly evaluated the records extracted from the Huns, Gokturks and Uyghurs in Chinese sources. Significant cultural issues such as the Chinese history, geography, literature and ethnology, which were not directly related to the Turkish history, were disregarded.

d) Since there was no coordination between the sinologists that conduced searches based on the Chinese sources, the outputs are not complementary to one another. For instance, even though an extensive work named "The Great Hun Empire" was written, an extensive work on the Hun-Chinese relationships was not yet written. On the other hand, a dictionary on Turkish or Chinese figures that lived during the Hun's or Gokturks' reign was not yet released.

e) No attempt has yet been made to produce fundamental reference works and dictionaries such as well-known figures, titles and toponomies needed for researches on the history, literature and ethnology of the Central Asia.

f) Large university libraries and research centres in our country cannot provide periodicals published in Chinese on an uninterrupted basis, therefore experts that are capable of Chinese cannot closely follow up with the scientific research results there.

g) Majority of the books published on China in Turkey are works written based on second or third-hand sources in English, French or German, which do not provide detailed information on Chinese history and culture with an absence of Chinese skills. Authors of such works have no information on the transcription of Chinese words, and are prone to make mistakes when it comes to express Chinese words in Latin, and it is mostly not possible to what they mean.

h) Even though all our academicians and executives engaged in sinology and history take every single 
opportunity to express and emphasise that the Chinese sources are utterly important and significant for our culture and history, they somehow do not make any reference to translation and evaluation of the portion of those sources related to our history and culture. The Turkish Historical Society made such an attempt in the early 2000s, and the part relating to the Huns in 'Önceki Han Hanedan1/The Former Hun Dynasty', and the part relating to the Gokturks in 'Önceki Tang Hanedani/The Former Tang Dynasty' were both translated and evaluated, whereas portions relating to the former Turkish history and culture in the remaining 22 Chinese annuals remain untouched.

\section{Conclusion}

Having started only after 12 years following the foundation of the modern turkey, sinology researches was led by the western sinologists until 1948, thus it managed to catch up with the international level, however sinology researches in our country receded quickly since the second half of the $20^{\text {th }}$ century until today. Following the end of World War II, greater countries polarised with others to form allies, thus China was positioned itself in the opposite of western countries; while modern western world made great efforts to understand and position China and to take better advantage of its economic and cultural opportunities, China was however perceived, in Turkey, as a mysterious and "traditionally weird foreign land" that should be checked from classical sources, failing to better understand it or to set a strategy on the short or long run. Turkey did not take any step to establish a diplomatic and cultural relationship with China until 1971, and could not discover it until the Opening Policy of China. Consequently, sinology in Turkey did not set the target of understanding China until the given date, but intended to look up for and reveal the traces of its ancestors in classical Chinese courses. As a natural consequence of this, the studies on sinology were substantially limited to the works revealed for the aforecited purposes.

From a general perspective, it should be understood that a substantial part of the works conducted on China in our country is limited to sinology works that rely on Classical China. All living organisms evolve and develop, likewise perceivable changes occur in this area, too. Modern world attempts to understand China not only for its historical background but also for all its aspects from the first hand source, and forms Chinese policies and strategies for understanding China according to the data acquired. All these serious and extensive targets expressed herein with regards to China are not fully covered by the agenda of the experts of China in Turkey. Even though it has been recently abandoned to discuss the Chinese world from a perspective based on the opinions produced until the half of the $20^{\text {th }}$ century by the western sinologists, experts on China in Turkey should make more reasonable efforts to understand China and should discuss China of the $21^{\text {st }}$ century from a perspective of the modern western world. Today, the information age facilitates the scientific life in all aspects and Turkey and China, as two old friends are no longer rivals in the Far Asia, Middle East, and Africa but are cooperation partners. Turkey has even a narrower perspective of China than that of the western in the $21^{\text {st }}$ century, therefore it should abandon the traditional approach of the last century. Turkey should already begin to approach a perspective of its own to China, which is only possible to have as many experts of China as possible that are capable of evaluating Chinese world in the light of the materials in Chinese.

\section{References}

[1] BARTHOLD Wilhelm von, Orientalism in Russia and Europe, Translated By Kaya bayraktar-Ayşe meral, Küre Publications, İstanbul 2004.

[2] Çin Denemeleri-Dünya Edebiyatından Seçmeler, Çev: Wofram Eberhard-Nusret Hızır, Milli Eğitim Bakanlığı Yayınları, İstanbul 1989.

[3] EBERHARD Wolfram, Çin'in Şimal Komşuları, Çev: Nimet Uluğtuğ, Türk Tarih Kurumu Yayınevi, Ankara 1996.

[4] EBERHARD Wolfram, ÇíN_Sinoloji’ye Giriş, Ter: İkbal Berk, Pulhan Matbaası, İstanbul 1946.

[5] EBERHARD Wolfram, History of china, Translated by İkbal berk, Turkish Historical Society Publications, Ankara 1995.

[6] GENG Sheng, Faguo Hanxue Shi Lun (On History of Sinology in France), Xueyuan Publishing House, Beijing 2015.

[7] GÖDE Kemal, Hocamı prof. Dr. Bahaeddin Ögel (19241989), Erciyes University Journal of Social Sciences Institute, Issue 4.

[8] LIU Zheng, Haiwai Hanxue Yanjiu (Chinese Studies in Overseas), Wuhan University Publication House, Wuhan 2002.

[9] MENG Qingbo, "Hebei Yu Haiwai Hanxue Yanjiu (Hebei and Chinese Studies in Overseas)", Journal of Wuhan Technical University), 2014 Issue 2.

[10] SEZEN Seriye, China Before the Revolution from the Eyes of a Turkish Sinologist: Notes from the Old China, Ankara Journal of University's Faculty of Languages, History and Geography Journal, Issue 51/2 2011.

[11] XIONG Wenhua, Yingguo Hanxue Shi (History of Sinology in England), Xueyuan Publishing House, Beijing 2007.

[12] ZHANG Xiaomin, "Haiwai Zhongguoxue Yanjiu Xueke Jianshe Chu (About Construction of Chinese Studies in Overseas)", Guoji Hanxue (International Sinology), 2012 Issue 1. 